\title{
Deformation of single cells - Optical two-beam traps and more
}

Nielsen, Kirstine Sandager; Rungling, Tony B.; Dziegiel, Morten Hanefeld; Marie, Rodolphe; BergSørensen, Kirstine

Published in:

Complex Light and Optical Forces XIII

Link to article, DOI:

$10.1117 / 12.2513407$

Publication date:

2019

Document Version

Publisher's PDF, also known as Version of record

Link back to DTU Orbit

Citation (APA):

Nielsen, K. S., Rungling, T. B., Dziegiel, M. H., Marie, R., \& Berg-Sørensen, K. (2019). Deformation of single cells - Optical two-beam traps and more. In E. J. Galvez, D. L. Andrews, \& J. Gluckstad (Eds.), Complex Light and Optical Forces XIII [1093516] SPIE - International Society for Optical Engineering. Proceedings of SPIE The International Society for Optical Engineering Vol. 10935 https://doi.org/10.1117/12.2513407

\section{General rights}

Copyright and moral rights for the publications made accessible in the public portal are retained by the authors and/or other copyright owners and it is a condition of accessing publications that users recognise and abide by the legal requirements associated with these rights.

- Users may download and print one copy of any publication from the public portal for the purpose of private study or research.

- You may not further distribute the material or use it for any profit-making activity or commercial gain

- You may freely distribute the URL identifying the publication in the public portal 


\section{Deformation of single cells - optical two-beam traps and more}

Kirstine Sandager Nielsen, Tony B. Rungling, Morten Hanefeld Dziegiel, Rodolphe Marie, Kirstine BergSørensen

Kirstine Sandager Nielsen, Tony B. Rungling, Morten Hanefeld Dziegiel, Rodolphe Marie, Kirstine Berg-Sørensen, "Deformation of single cells optical two-beam traps and more," Proc. SPIE 10935, Complex Light and Optical Forces XIII, 1093516 (1 March 2019); doi: 10.1117/12.2513407

SPIE. Event: SPIE OPTO, 2019, San Francisco, California, United States 


\title{
Deformation of single cells - optical two-beam traps and more
}

\author{
Kirstine Sandager Nielsen ${ }^{\mathrm{a}}$, Tony B. Runglinga ${ }^{\mathrm{a}}$, Morten Hanefeld Dziegiel ${ }^{\mathrm{b}}$, Rodolphe Marie ${ }^{\mathrm{c}}$, \\ and Kirstine Berg-Sørensen ${ }^{a}$

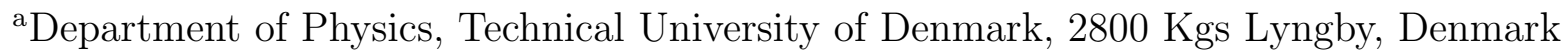 \\ ${ }^{\mathrm{b} B}$ Blood Bank, University Hospital Copenhagen, 2100 Copenhagen, Denmark \\ ${ }^{c}$ Department of Health Technology, Technical University of Denmark, 2800 Kgs Lyngby, \\ Denmark
}

\begin{abstract}
An optical two-beam trap composed from two counter propagating laser beams is an interesting setup due to the ability of the system to trap, hold, and stretch soft biological objects like vesicles or single cells. Because of this functionality, the system was also named the optical stretcher by Jochen Guck, Josep Käs and co-workers almost 20 years ago (J. Guck et al, Biophys. J. 81, 767 (2001)). In a favorable setup, the two opposing laser beams meet with equal intensities in the middle of a fluidic channel in which cells may flow past, be trapped, stretched, and allowed to move on, giving the promise of a high throughput device. Yet, single beam optical traps, aka optical tweezers, by far outnumber the existing optical stretchers in research labs throughout the world. The ability to easily construct an optical stretcher setup in a low-cost material would possibly imply more frequent use of the optical stretching technique. Here, we discuss advantages and disadvantages of choice of material and methodology for chip assembly and chip production. For high throughput investigations of stretching deformation of single cells, optical stretching is, however, out-performed by hydrodynamic deformability assays. As we will discuss, injection molded polymer chips may with advantage be applied both for optical stretching and for hydrodynamic deformability experiments.
\end{abstract}

Keywords: Optical and hydrodynamic stretching, polymer microfluidic chips, single cell biophysics, red blood cells

\section{INTRODUCTION}

The desire to determine mechanical characteristics of single cells is driven by indications that certain pathologies are related to a difference in elasticity of cells from a healthy person versus those originating from a patient, see e.g. Ref. 1. Optical trapping technology has contributed both in terms of assays with two single-beam optical traps manipulating handles attached to the surface of a single red blood cell, ${ }^{2}$ or the boundaries of a single red blood cell, ${ }^{3,4}$ or more readily combined with microfluidic delivery in the so-called optical stretcher. ${ }^{5}$ Various successful results using such devices for mechanical studies of single cells of different origin have been reported in the literature. ${ }^{6-10}$

The interest in mechanical investigations of single cells or monolayers of cells have resulted in development of several techniques whose complementary was recently discussed in Ref. 11. Both due to their potential use as diagnostic markers, and their abundance and availability, single cells from blood have received particular interest, ${ }^{12-16}$ and are often used as first cell type for a new methodology, see e.g. Ref. 17. In terms of throughput, recent literature have demonstrated the superiority of hydrodynamic deformability assays with single cell image analysis, in some cases even in real time.${ }^{18-23}$ When high throughput is the target, hydrodynamic deformability assays thus outperforms optical stretching assays as such. Nevertheless, we envision that future development may combine sorting based on high throughput abilities of hydrodynamic deformability assays with the opportunities of more detailed single cell investigations offered by optical trapping methodology.

Further author information: (Send correspondence to K.B.-S.)

K.B.-S.: E-mail: kirstine.berg-sorensen@fysik.dtu.dk, Telephone: +45 45253101

Complex Light and Optical Forces XIII, edited by Jesper Glückstad, David L. Andrews,

Enrique J. Galvez, Proc. of SPIE Vol. 10935, 1093516 · (c) 2019 SPIE

CCC code: $0277-786 \mathrm{X} / 19 / \$ 18 \cdot$ doi: $10.1117 / 12.2513407$

Proc. of SPIE Vol. 10935 1093516-1 
Seen from an engineering perspective, the construction of optical stretchers in a microfluidic chip may start with a decision on the chip material and chip production method. Next, since proper optical stretching relies on a good alignment of two counter-propagating and preferentially TEM00 Gaussian beams, means of light delivery should be decided. Last, since the optical stretching zone within the microfluidic channel is highly localized, also vertically, a larger fraction of the population of the cells may reach the optical stretching zone if vertical position control is considered too. Below, options for all of these engineering choices will be discussed.

As will be discussed, for the optical stretcher setup, injection molded polymer chips, in which single mode commercial optical fibers are mounted, offers a good compromise in the various design choices. Alas, injection molded polymer chips are also well suited for setups focused on hydrodynamic deformability, and the final sections of the manuscript will describe one such chip design and provide preliminary results on large samples of red blood cells.

\section{DESIGN CONSIDERATIONS FOR OPTICAL STRETCHER ASSAYS}

The original design of a microfluidic stretcher by the Guck-group ${ }^{5}$ is based on a square capillary mounted in an SU-8 structure with grooves for the optical fibers perpendicular to the square slit for the square capillary. In this original work, vertical position control was addressed by creation of different vertical depths of the fiber grooves with respect to the depth of the groove for the square capillary within the SU-8 structure, and repositioning of the optical fibers with each new cell sample type (J. Guck, private communication). Our focus has been to investigate other implementations of vertical position control as well as low cost, potentially single use, microfluidic solutions, preferably allowing for parallel processing. The latter can be obtained with designs based on hard polymer materials, either processed by hot embossing ${ }^{24}$ and certainly so when processed by injection molding. ${ }^{25,26}$ Our current preference is for a simple design of an injection molded polymer chip,${ }^{25}$ the design of which is illustrated in Fig. 1B.

Table 1. Design options attempted in our lab

\begin{tabular}{|l|l|l|}
\hline Chip material & Light delivery & Vertical position control \\
\hline Fused silica & Waveguides by femto-second laser writing & Acoustic forces \\
\hline Hard polymer materials (TOPAS) & Single mode optical fibers & None $^{25}$ \\
\hline Hard polymer materials (TOPAS) & Single mode optical fibers & Hydrodynamic forces $^{26}$ \\
\hline Hard polymer materials (PMMA) & UV inscribed waveguides & None $^{24}$ \\
\hline Soft polymer materials (PDMS) & Single mode optical fibers & Acoustic forces $^{29}$ \\
\hline
\end{tabular}

Table 1 summarizes the designs investigated in our previous work, already to a large extent reviewed in Ref. 30. Details of the experimental setup may be found in the papers referenced in the table. In brief, the simplest design is based on rapid prototyping of the fluidic channel in Polydimethylsiloxane (PDMS) in which fiber grooves are molded too. This chip was constructed without any clean-room work. The PDMS unit is bonded to a glass lid and a glass bottom by means of plasma bonding in an oxygen plasma. Fluidic inlets are drilled in the glass lid prior to bonding. For vertical position control, the unit is positioned on a piezo crystal with a resonance frequency matching the height of the fluidic channel. ${ }^{29}$ The same vertical position control works even better with a microfluidic chip created purely in fused silica. ${ }^{27}$ In this case, light delivery was achieved by femto-second laser written waveguides, obtained in a manner similar to that described in Ref. 31. By such direct inscription of the light delivery solution, alignment is perfect. The disadvantage of the solution is loss of laser power both within the waveguides and in the coupling between the fiber-coupled laser and the waveguide of the chip.

For parallel processing in polymer materials, we have investigated both Poly(methyl methacrylate) (PMMA) and the Cyclic olefin copolymer (COC) TOPAS ${ }^{\circledR}$ grade 5013. For the microfluidic chip created in PMMA, a straight fluidic channel was obtained by hot embossing, and perpendicular waveguides by UV modification of 
the refractive index of the PMMA. ${ }^{24}$ As for the glass chips, this solution suffers from loss of laser power both within the waveguides and in the coupling between the fiber-coupled laser and the waveguide of the chip. No vertical position control was attempted with this microfluidic solution.

The injection molded polymer chips investigated in Refs. 25,26 requires substantial clean-room processing for the creation of the Ni-shim that is used in the injection molding process, but once the mold is there, thousands of presumably identical microfluidic chips can be available. By the choice of designs that include commercial optical fibers for light delivery, the problem of a lossy coupling between laser and microfluidic system is avoided. Implementation of vertical position control by acoustic forces in a polymer material is, however, not straightforward, due to the relatively low sound speed and acoustic impedance in most transparent plastics. This implies that acoustic energy may be transferred to, and lost in, the device itself, and detailed 3D modeling of the pressure fields in the entire device is required in order to find the conditions for acoustic resonance. ${ }^{32}$ As an alternative, vertical position control may be achieved passively by flow focusing that only requires channels to be defined at different depths on the master. Such vertical position control through choice of 3D design of the microfluidic channels has been attempted, ${ }^{26}$ but discontinued due to lack of resources.

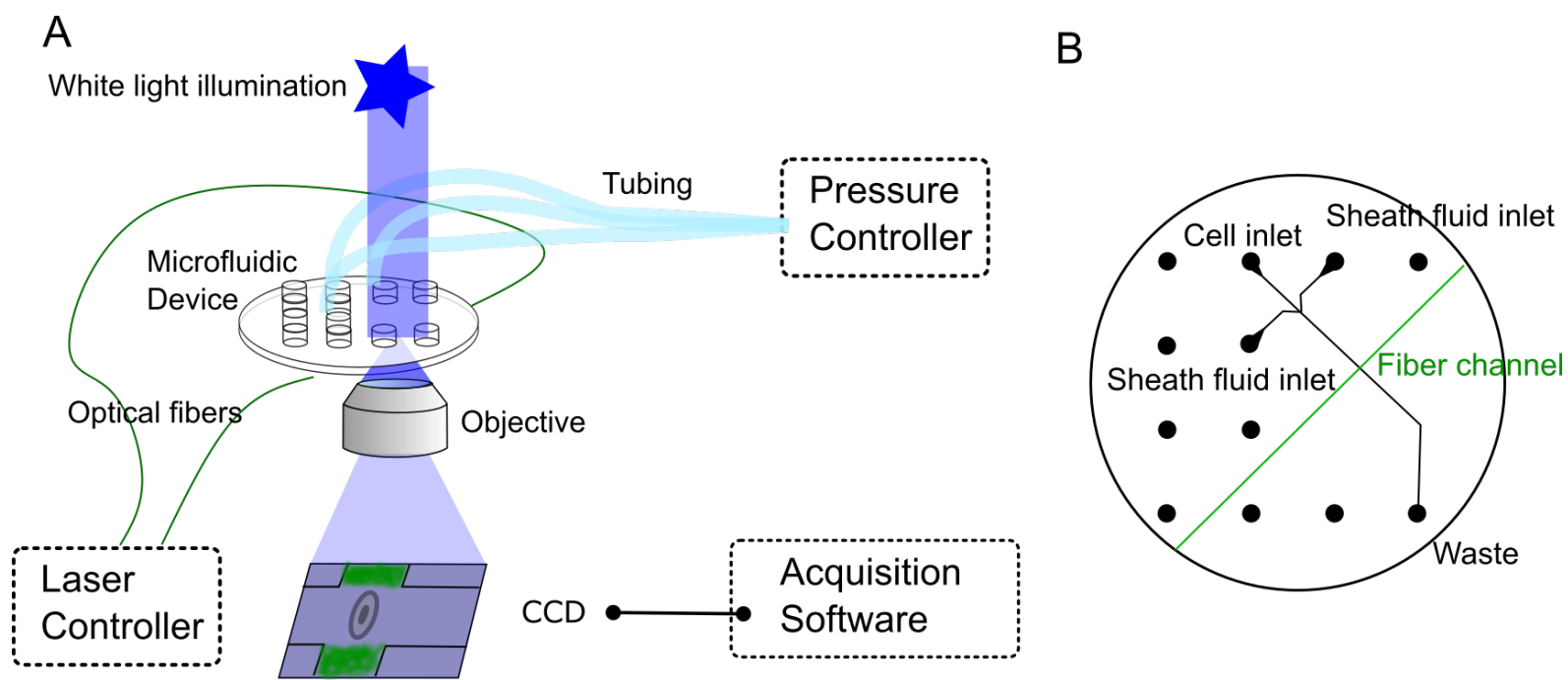

Figure 1. Illustration of the optical stretcher setup based on an injection molded microfluidic chip. Part A sketches how the microfluidic chip is connected to laser- and pressure control, and visualization within a standard bright field optical microscope, equipped with a CCD camera. Details may be found in Ref. 25. Part B provides a more detailed overview of the injection molded microfluidic chip, with channels for the fluidics as well as channels for the optical fibers. Four out of 12 available LUER fittings from the injection molding tool are used for fluidic connection. The core of the experiment, the optical stretching itself, takes place where the two channels cross - a location also sketched in the zoom at the bottom of part A.

\section{HYDRODYNAMIC STRETCHING IN INJECTION MOLDED CHIP}

As already discussed, single cell deformability studies with high throughput, i.e. thousands of cells per second, is more readily obtained by hydrodynamic forcing through microfluidic design. ${ }^{18,19}$ One option relies on deformation by the soft cell as it passes through a microfluidic constriction, and visualization at high speed. ${ }^{19}$ Our take on this approach is to conduct the experiments in an injection molded polymer chip, with one particular design illustrated in Fig. 2A. This setup has been used in studies of red blood cells from adult donors, as well as from umbilical cord samples, obtained right after the birth of a healthy newborn.

\subsection{Experimental methods}

The microfluidic chip consists of eight parallel channels each leading to a common outlet channel via a microfluidic constriction, see Fig. 2A. All channels are defined at a single depth of $30 \mu \mathrm{m}$. The outlet channels are $100 \mu \mathrm{m}$ 
A

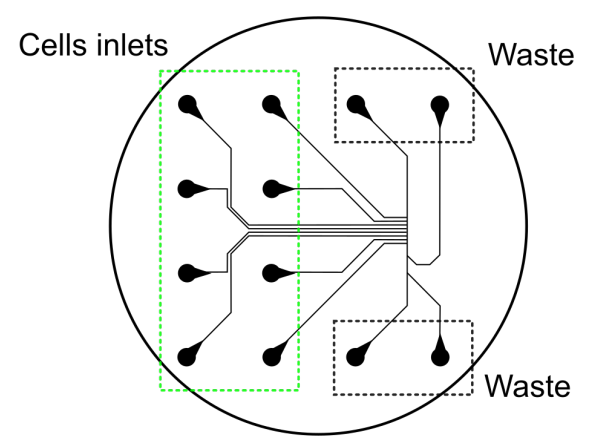

C White light illumination
B

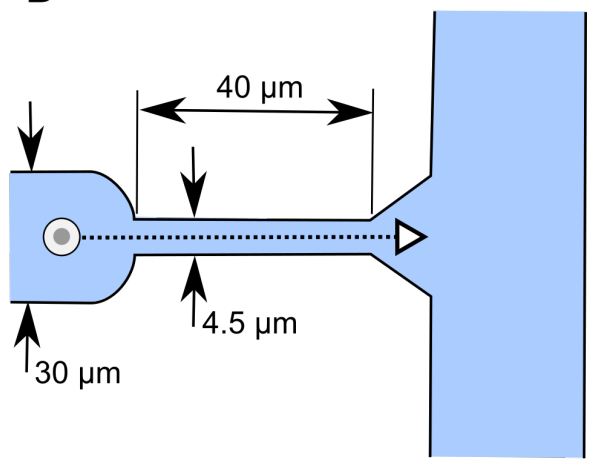

Tubing

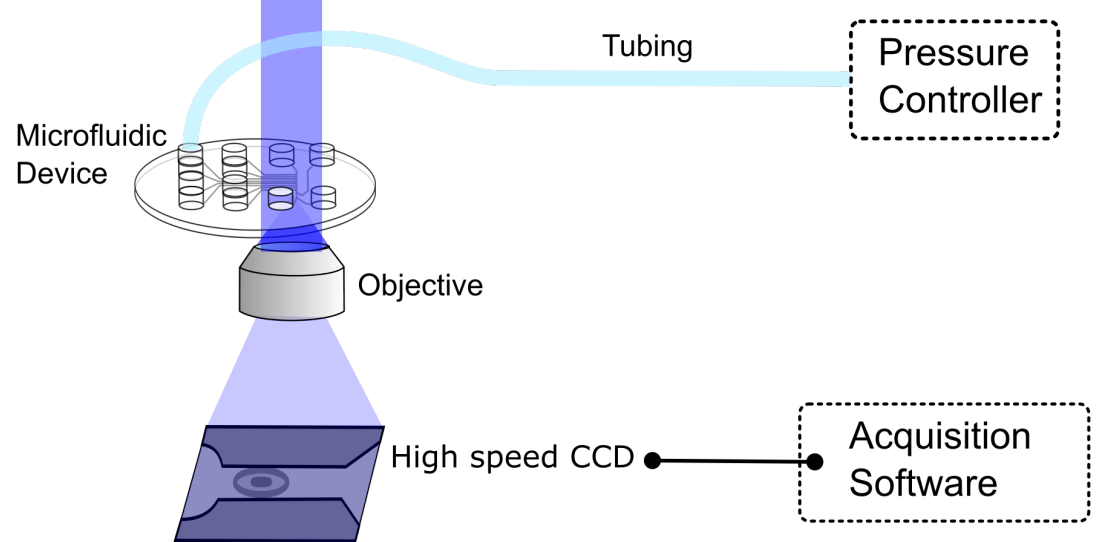

Figure 2. Illustration of a setup for hydrodynamic deformability determination, based on an injection molded microfluidic chip. Part A provides an overview of the injection molded microfluidic chip, with channels for the fluidics. This includes 8 inlets that may be used for diluted cell samples. In the experiments below, we used two of these. Part B illustrates the core of the experiment, where red blood cells enter a constriction and are imaged under constant flow. Part $\mathrm{C}$ shows how the microfluidic chip is connected to pressure control, and visualization within a standard bright field optical microscope, equipped with a high speed CCD camera with corresponding acquisition software.

wide, whereas the microfluidic constriction have a minimum width of $4.5 \mu \mathrm{m}$ at the bottom and $6.5 \mu \mathrm{m}$ at the top (Fig. 2B.).

A nickel shim for injection molding was fabricated using standard clean room processes. ${ }^{33}$ The devices were injection molded with the COC polymer TOPAS ${ }^{\circledR}$ grade 5013 with a melting temperature of $250^{\circ} \mathrm{C}$ using a mold temperature of $115^{\circ} \mathrm{C}$ and a shim temperature of $150{ }^{\circ} \mathrm{C}$, a holding pressure of 1155 bar and a cooling time of $15 \mathrm{~s}$, at a demolding temperature of maximum $135^{\circ} \mathrm{C}$. The injection molder (Engel) was equipped with a tool that creates 12 Luer fittings on each device. The Luer fittings are used as reservoirs containing up to $20 \mu \mathrm{L}$ of solution and are connected to a pressure controller (Fluigent MFCS EZ) to drive the sample from a reservoir through the corresponding constriction (Fig. 2C.).

The microfluidic channels on the injection molded parts are sealed with a $150 \mu \mathrm{m}$ thick TOPAS ${ }^{\circledR}$ grade 5013 foil using UV-assisted thermal bonding. Briefly, devices and lids are exposed to UV-light from a mercury arc lamp for $120 \mathrm{~s}$ before they are brought in contact and loaded for 3 minutes at $5.1 \mathrm{MPa}$ and a temperature of $125^{\circ} \mathrm{C}$ in a heated press $(\mathrm{P} / \mathrm{O} /$ Weber $)$. This creates a strong bond between the two surfaces without deformation of the microfluidic channels since $T_{g}$ of $\mathrm{TOPAS}^{\circledR} 5013$ is $130^{\circ} \mathrm{C}$. The microfluidic device is primed with ethanol at high pressure then filled with an aqueous buffer (CellStab, see details below) so it is ready to receive the blood 
sample.

\subsection{Experimental assay and protocol}

A small sample $(2.6 \mu \mathrm{l})$ of entire blood with anti-coagulant EDTA or heparin is diluted in $1 \mathrm{ml}$ of CellStab (BioRad Switzerland). A small amount $(20 \mu \mathrm{l})$ is then transferred to the relevant well in the microfluidic chip, and a flow is induced by applying a pressure of 4 mbar. The flow is visualized in an optical microscope (Zeiss Axiovert $200 \mathrm{M}$ with a $100 \times / 1.25$ Acroplan oil immersion objective), equipped with a high-speed camera (AOS S-motion). The setup is illustrated in Fig. 2C.

Image sequences of 80.000-160.000 images are recorded and saved on computer, before subsequent analysis by custom-made routines written in Matlab (R2016b and R2017a), as detailed below. A given microfluidic chip has been used for samples from up to 20 donors. Between each new sample, the chip is rinsed thoroughly with CellStab.

\subsection{Image analysis}

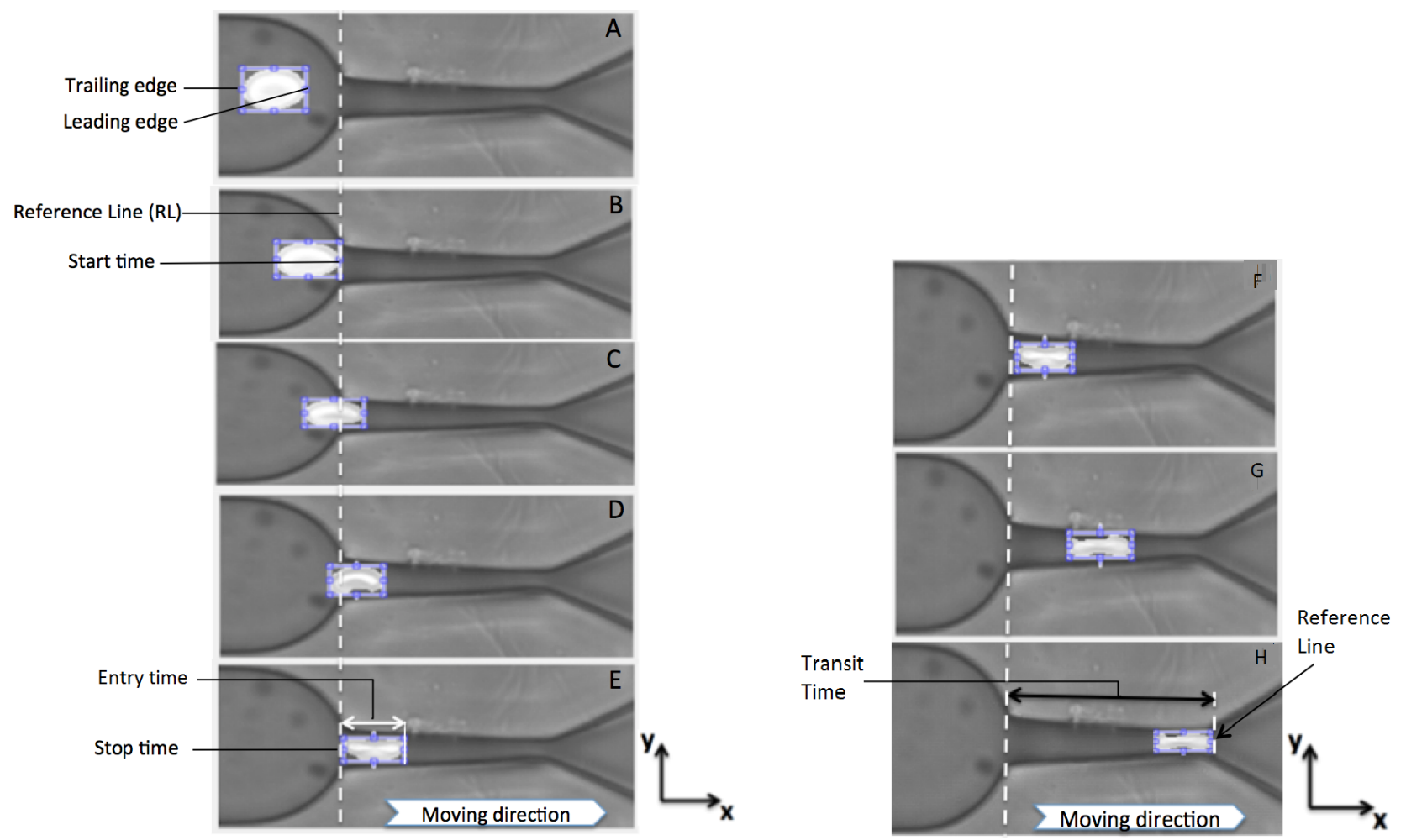

Figure 3. Images of a red blood cell on its passage through the microfluidic constriction. The left part, panels A-E, illustrates obtention of the characteristic time denoted "entrance time", whereas the right part, panels F-H, illustrates how the "transit time" is found. The entrance time is determined as the time between image B and image E whereas the transit time is determined at the time between image $\mathrm{F}$ and image $\mathrm{H}$.

Image analysis is carried out in two steps. First, images in which no cells are present are identified and subsequently used as background images that may be subtracted from images containing one or more cells. Next, individual cells are identified and followed in a series of subsequent images, typically a given cell appears in around 60-70 such subsequent images. At the same time, characteristic numbers describing the individual cell during its passage through the narrow constriction are determined. In a first round of analysis, efforts were concentrated on analysis of the ratio of entrance time to transit time, with the definition of the two times described in Fig. 3, inspired by work of others. ${ }^{16,34}$ The front-edge and back-edge positions, and the time-stamp of the individual images, are used to provide values for entrance time and transit time in the constriction channel. The box surrounding the cell is determined by converting the gray-scale image into a black-and-white image, 
and then using the inbuilt Matlab function regionprops to find the cell as a so-called connected component. The command regionprops then also provides a Bounding Box. These initial studies were used to check if there were any variations between measurements made in supposedly identical, injection molded microfluidic systems. We concentrated on the ratio of the two times rather than the times as such since any disturbances of the flow upstream or downstream, invisible to us during the experiment, would influence the absolute values of the times extracted, but not their ratio.

The image analysis provides a data set of 37887 adult cells, stemming from 99 adult donors, and 8549 fetal cells, stemming from 56 umbilical cord samples.

\subsection{Results and discussion}

First, the variation in the ratio of entrance time to transit time is investigated between individual samples, stemming from both adult and fetal donors. As an initial control experiment, results from independent measurements in the same chip with samples from the same donor were compared. Then, the mean value of the ratio of entrance time to transit time for each individual donor was found, and compared with that from other donors, with measurements either in the same chip or in a supposedly identical copy of the microfluidic chip. These latter results, shown in Fig. 4, suggests that variation in the ratio of entrance to transit time is due to variations between individual donors rather than due to a change of microfluidic chip. Unfortunately, measurements of samples from the same donor was not repeated with different copies of the chip.

In order to document the statistical variations, we performed ANOVA statistical tests, using the inbuilt functions fitglme and anova in Matlab R2017b, to check for variation both between individual donors and between different copies of the chip. For the latter, any variation observed is likely to be due to the manual mounting of the chip in the microscope and subsequent manual focusing which may result in slight differences in the imaging conditions rather than differences in the injection molded chip itself. We tested for the null hypothesis that neither chip-to-chip nor donor-to-donor variation should be significant. For both adult and fetal donors, the logarithm of the set of values for the time-ratio was used rather than the raw set of values for the time-ratio since the latter did not appear to be normally distributed. Rather, the distribution of the values for the raw time-ratio was skewed with a tail extending towards the larger values of the time-ratio.

For the adult donors, the null-hypothesis is accepted with a p-value of 0.2 for chip-to-chip but a low p-value of 0.03 for donor-to-donor significance. For the umbilical cord donors, the null-hypothesis is rejected. Further experiments are ongoing and will demonstrate to which extent the experimental assay is sufficiently reliable as basis for further model development and data analysis.

\section{SUMMARY}

We have demonstrated that injection molded microfluidic chips are promising devices both as basis for optical stretching experiments and for hydrodynamic deformability assays. One chip design for the latter has been investigated in this work, but in ongoing work, we compare this design with results in a design with more shallow fluidic channels. With shallow fluidic channels, cells are forced to stay in focus while passing through the constriction, and our preliminary results indicate a better ability to distinguish details in the images of the individual cells. For this purpose, we work with development of statistical models and potentially ability to distinguish cells that originate from donors of different age or pathology. ${ }^{35,36}$

\section{ACKNOWLEDGMENTS}

We acknowledge support from the PolyNano summer school and the PolyNano strategic research center, supporting KSN, and advice from Anders Nymark Christensen regarding ANOVA statistical tests. The measurements on hydrodynamic deformability of adult donors were conducted as part of the MSc thesis of TBR. 

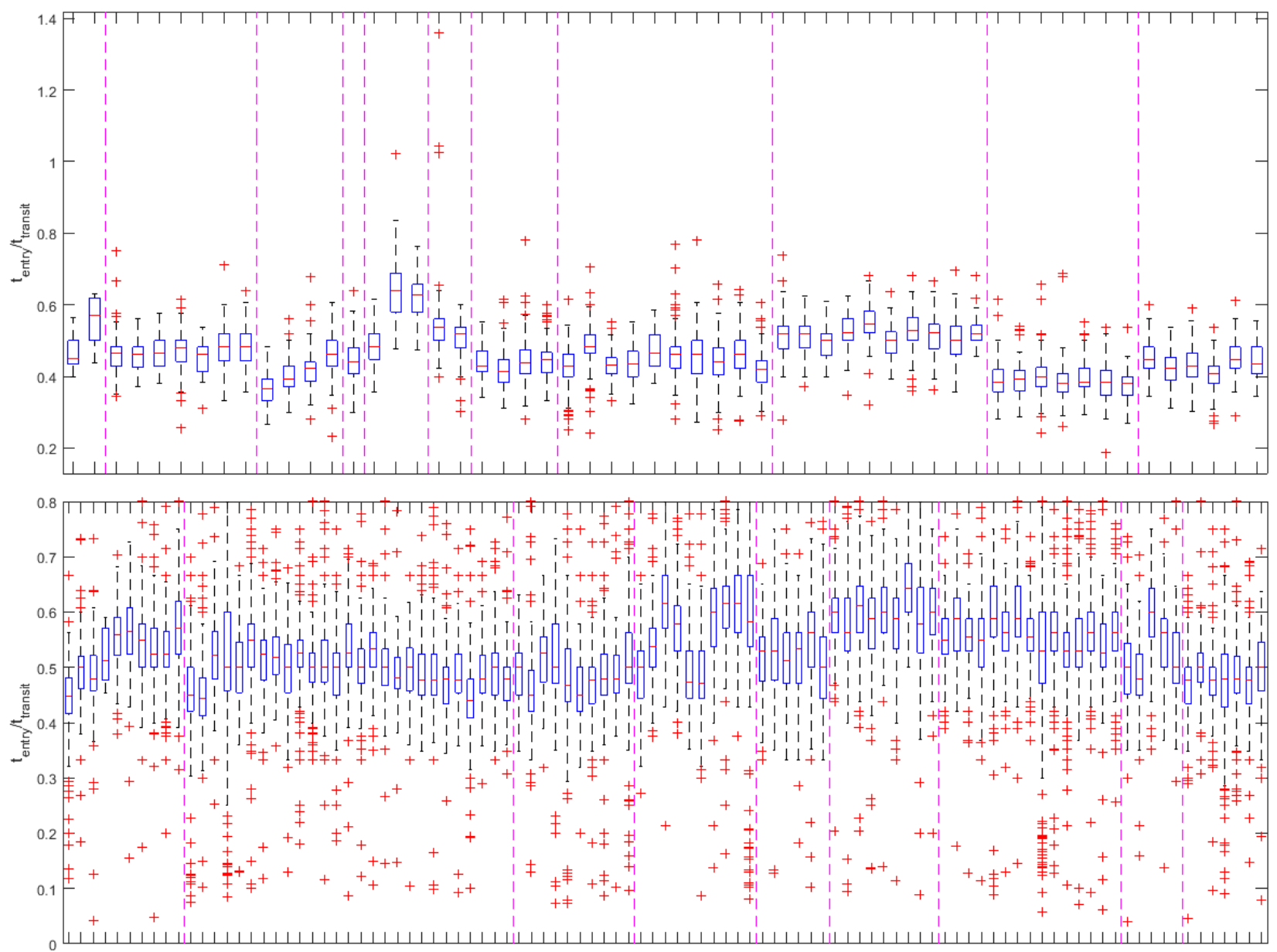

Figure 4. Figure showing the results of the measurements of the ratio of entrance time to transit time, with the mean value found from measurements on between 200 and 400 cells for each of the 59 individual umbilical cord donors (upper part) and each of the individual 101 adult donors (lower part). Blue boxes indicate the standard deviation, with red horisontal line as the median. Red crosses indicate outliers. Dashed purple vertical lines indicate change of microfluidic chip.

\section{REFERENCES}

[1] Guck, J., Schinkinger, S., Lincoln, B., Wottawah, F., Ebert, S., Romeyke, M., Lenz, D., Erickson, H. M., Ananthakrishnan, R., Mitchell, D., Käs, J., Ulvick, S., and Bilby, C., "Optical deformability as an inherent cell marker for testing malignant transformation and metastatic competence.," Biophysical journal 88(5), 3689-3698 (2005).

[2] Lenormand, G., Henon, S., Richert, A., Simeon, J., and Gallet, F., "Direct measurement of the area expansion and shear moduli of the human red blood cell membrane skeleton," Biophys. J. 81, 43-56 (2001).

[3] Dao, M., Lim, C. T., and Suresh, S., "Mechanics of the human red blood cell deformed by optical tweezers," Journal of the Mechanics and Physics of Solids 51(11-12), 2259-2280 (2003).

[4] Rusciano, G., "Experimental analysis of $\mathrm{Hb}$ oxy-deoxy transition in single optically stretched red blood cells," Physica Medica 26(4), 233-239 (2010).

[5] Lincoln, B., Erickson, H. M., Schinkinger, S., Wottawah, F., Mitchell, D., Ulvick, S., Bilby, C., and Guck, J., "Deformability-based flow cytometry," Cytometry 59A(2), 203-209 (2004).

[6] Remmerbach, T. W., Wottawah, F., Dietrich, J., Lincoln, B., Wittekind, C., and Guck, J., "Oral cancer diagnosis by mechanical phenotyping," Cancer Res. 69, 1728-1732 (2009). 
[7] Lautenschlager, F., Paschke, S., Schinkinger, S., Bruel, A., Beil, M., and Guck, J., "The regulatory role of cell mechanics for migration of differentiating myeloid cells," Proc Natl Acad Sci U S A 106, 15696-15701 (2009).

[8] Maloney, J. M., Nikova, D., Lautenschlager, F., Clarke, E., Langer, R., Guck, J., and Van Vliet, K. J., "Mesenchymal stem cell mechanics from the attached to the suspended state," Biophysical Journal 99, 2479-2487 (2010).

[9] Whyte, G., Lautenschläger, F., Kreysing, M., Boyde, L., Ekpenyong, A., Delabre, U., Chalut, K., Franze, K., and Guck, J., "Dual-beam Laser Traps in Biology and Medicine: When One Beam is Not Enough," Proc. of SPIE 7762, 77620G-1-6 (2010).

[10] Ekpenyong, A. E., Whyte, G., Chalut, K., Pagliara, S., Lautenschläger, F., Fiddler, C., Paschke, S., Keyser, U. F., Chilvers, E. R., and Guck, J., "Viscoelastic Properties of Differentiating Blood Cells Are Fate- and Function-Dependent," PLOS ONE 7(9) (2012).

[11] Wu, P.-H., Aroush, D. R.-B., Asnacios, A., Chen, W.-C., Dokukin, M. E., Doss, B. L., Durand-Smet, P., Ekpenyong, A., Guck, J., Guz, N. V., Janmey, P. A., Lee, J. S. H., Moore, N. M., Ott, A., Poh, Y.-C., Ros, R., Sander, M., Sokolov, I., Staunton, J. R., Wang, N., Whyte, G., and Wirtz, D., "A comparison of methods to assess cell mechanical properties," Nature Methods 15(7), 491-498 (2018).

[12] Diez-Silva, M., Dao, M., Han, J., Lim, C.-T., and Suresh, S., "Shape and Biomechanical Characteristics of Human Red Blood Cells in Health and Disease.," MRS bulletin / Materials Research Society 35(5), 382-388 (2010).

[13] Rancourt-Grenier, S., Wei, M.-T., Bai, J.-J., Chiou, A., Bareil, P. P., Duval, P.-L., and Sheng, Y., "Dynamic deformation of red blood cell in dual-trap optical tweezers.," Optics express 18(10), 10462-10472 (2010).

[14] Haque, M. M., Moisescu, M. G., Valkai, S., Dér, A., and Savopol, T., "Stretching of red blood cells using an electro-optics trap," Biomedical Optics Express 6(1), 118 (2015).

[15] Park, H., Ahn, T., Kim, K., Lee, S., Kook, S.-y., Lee, D., Suh, I. B., Na, S., and Park, Y., "Threedimensional refractive index tomograms and deformability of individual human red blood cells from cord blood of newborn infants and maternal blood," Journal of Biomedical Optics 20, 111208 (aug 2015).

[16] Nyberg, K. D., Scott, M. B., Bruce, S. L., Gopinath, A. B., Bikos, D., Mason, T. G., Kim, J. W., Choi, H. S., and Rowat, A. C., "The physical origins of transit time measurements for rapid, single cell mechanotyping," Lab Chip 16(17), 3330-3339 (2016).

[17] Holmes, D., Whyte, G., Bailey, J., Vergara-Irigaray, N., Ekpenyong, A., Guck, J., and Duke, T., "Separation of blood cells with differing deformability using deterministic lateral displacement().," Interface focus 4(6), 20140011 (2014).

[18] Gossett, D. R., Tse, H. T. K., Lee, S. a., Ying, Y., Lindgren, A. G., Yang, O. O., Rao, J., Clark, A. T., and Di Carlo, D., "Hydrodynamic stretching of single cells for large population mechanical phenotyping," Proc. Nat. Acad. Sci. USA. 109(20), 7630-7635 (2012).

[19] Otto, O., Rosendahl, P., Mietke, A., Golfier, S., Herold, C., Klaue, D., Girardo, S., Pagliara, S., Ekpenyong, A., Jacobi, A., Wobus, M., Töpfner, N., Keyser, U. F., Mansfeld, J., Fischer-Friedrich, E., and Guck, J., "Real-time deformability cytometry: on-the-fly cell mechanical phenotyping.," Nature Methods 12(3), 199-202, 4 p following 202 (2015).

[20] Mietke, A., Otto, O., Girardo, S., Rosendahl, P., Taubenberger, A., Golfier, S., Ulbricht, E., Aland, S., Guck, J., and Fischer-Friedrich, E., "Extracting Cell Stiffness from Real-Time Deformability Cytometry: Theory and Experiment," Biophysical Journal 109(10), 2023-2036 (2015).

[21] Toepfner, N., Herold, C., Otto, O., Rosendahl, P., Jacobi, A., Krater, M., Stachele, J., Menschner, L., Herbig, M., and Ciuffreda, L., "Detection Of Human Disease Conditions By Single-Cell Morpho-Rheological Phenotyping Of Whole Blood," eLife 7, e29213 (2017).

[22] Herbig, M., Mietke, A., Müller, P., and Otto, O., "Statistics for real-time deformability cytometry: Clustering, dimensionality reduction, and significance testing," Biomicrofluidics 12(4) (2018).

[23] Urbanska, M., Rosendahl, P., Kräter, M., and Guck, J., "High-throughput single-cell mechanical phenotyping with real-time deformability cytometry," Methods in Cell Biology 147, 175-198 (2018).

[24] Khoury, M., Vannahme, C., Sørensen, K. T., Kristensen, A., and Berg-Sørensen, K., "Monolithic integration of DUV-induced waveguides into plastic microfluidic chip for optical manipulation," Microelectronic Engineering 121, 5-9 (2014). 
[25] Matteucci, M., Triches, M., Nava, G., Kristensen, A., Pollard, M. R., Berg-Sorensen, K., and Taboryski, R. J., "Fiber-Based, Injection-Molded Optofluidic Systems: Improvements in Assembly and Applications," Micromachines 6, 1971-1983 (dec 2015).

[26] Espina Palanco, M., Catak, D., Marie, R., Matteucci, M., Bilenberg, B., Kristensen, A., and Berg-Sørensen, K., "Optical two-beam trap in a polymer microfluidic chip," Proceeding of SPIE 992213, 992213 (2016).

[27] Nava, G., Bragheri, F., Yang, T., Minzioni, P., Osellame, R., Cristiani, I., and Berg-Sørensen, K., "All-silica microfluidic optical stretcher with acoustophoretic prefocusing," Microfluidics and Nanofluidics 19, 837-844 (2015).

[28] Yang, T., Bragheri, F., Nava, G., Chiodi, I., Mondello, C., Osellame, R., Berg-Sørensen, K., Cristiani, I., and Minzioni, P., "A comprehensive strategy for the analysis of acoustic compressibility and optical deformability on single cells," Sci. Reports 6, 23946 (2016).

[29] Khoury, M., Barnkob, R., Busk, L., Tidemand-Lichtenberg, P., Bruus, H., and Berg-Sørensen, K., "Optical stretching on chip with acoustophoretic prefocusing," Proceeding of SPIE 8458, 84581E-84581E-11 (2012).

[30] Berg-Sørensen, K., "Optical two-beam traps in microfluidic systems," Japanese Journal of Applied Physics 55, 08RA01 (2016).

[31] Bellini, N., Vishnubhatla, K. C., Bragheri, F., Ferrara, L., Minzioni, P., Ramponi, R., Cristiani, I., and Osellame, R., "Femtosecond laser fabricated monolithic chip for optical trapping and stretching of single cells," Optics Express 18(5), 4679-4688 (2010).

[32] Dual, J. and Möller, D., "Acoustofluidics 4: Piezoelectricity and application in the excitation of acoustic fields for ultrasonic particle manipulation," Lab on a Chip 12, 506-514 (2012).

[33] Utko, P., Persson, F., Kristensen, A., and Larsen, N. B., "Injection molded nanofluidic chips: fabrication method and functional tests using single-molecule DNA experiments," Lab Chip 11, 303-308 (2011).

[34] Gabriele, S., Benoliel, A. M., Bongrand, P., and Théodoly, O., "Microfluidic investigation reveals distinct roles for actin cytoskeleton and myosin II activity in capillary leukocyte trafficking," Biophysical Journal 96, 4308-4318 (2009).

[35] Thirstrup, H., "Development of methods for determining red blood cell deformability," MSc Thesis, Technical University of Denmark (2016).

[36] Aagesen, L., "Hydrodynamic Deformability-based Classification of Fetal and Adult Red Blood Cells Using Image Analysis and Machine Learning," MSc Thesis, Technical University of Denmark (2018). 